\title{
Mathematics as a Social Construct: Teaching Mathematics in Context
}

\author{
Hayley Barnes and Elsie Venter \\ University of Pretoria \\ hayley.barnes@up.ac.za and elsie.venter@up.ac.za
}

\begin{abstract}
Why is teaching in context an important option to consider in the teaching of mathematics? What does it mean to teach mathematics from and in contexts? And what are the possible challenges associated with this practice? The aim of this paper is not to provide a comprehensive answer or solution to these questions. We attempt rather to address these questions specifically with regard to South Africa and the theory of Realistic Mathematics Education. In this article we consider a vignette of a more formal and traditional mathematics lesson and then suggest possible reasons why we need to be teaching more in context. Furthermore we discuss the application of the theory of Realistic Mathematics Education as a potential approach to facilitate teaching in context. Finally we present some challenges associated with this practice.
\end{abstract}

The philosophical shift that has occurred within the domain of mathematics has brought with it a wave of reform in mathematics education. The former absolutist paradigm that dominated undermined the social responsibility of mathematics in human affairs such as value, wealth and power (Ernest, 1991). The shift has challenged the infallibility of mathematics and acknowledged it as a product of human inventiveness (Davis \& Hersh, 1980) and a human activity (Freudenthal, 1973), thus making it a social construct. While the reform propagating the teaching of mathematics as a social construct is a positive move, along with the introduction of mathematical literacy in many countries, how can we effectively implement this reform? This paper seeks to examine the area of teaching mathematics in context (specifically in relation to the theory of Realistic Mathematics Education) to support this reform and the implementation thereof in school and tertiary education.

A vignette of a traditional formal mathematics lesson is first simulated, followed by a discussion of mathematics as a social construct. The relevance of teaching in context is then explored while alluding to the theory of Realistic Mathematics Education as a vehicle through which this can be done. Examples of studies conducted at secondary and tertiary level are considered, concluding with some challenges of teaching in context.

\section{A lesson simulation}

The following vignette of a lesson will probably be familiar to many readers:

Today's lesson is going to look at rounding off decimals to the nearest whole number. Let us first revise the concept of rounding off. Remember that rounding off helps us in estimation. Last year you learnt to round off to the nearest ten, hundred and thousand. You did this by looking at which ten, hundred or thousand the number you are rounding off is closest to. Let's look at an example. Write this down in your books if you have forgotten how to round off:

Example 1: Round 63 off to the nearest ten.

On the number line 63 lies between 60 and 70. It lies closer to 60 though so we round it off to 60 , as the nearest ten. Remember also that in this case, if the units digit is less than the number 5, we round down to the nearest ten.

Example 2: Round 2499 off to:

a) the nearest ten

b) the nearest hundred

c) the nearest thousand

a) Let us start by looking at the units digit. It is more than 5 so we round up to the nearest ten. The answer is therefore: 2500 
b) Now we need to look at the tens digit because we are rounding off to the nearest hundred. It is also more than 5 so we round up to the next hundred. Answer: 2500

c) For rounding off to the nearest thousand we look at the hundreds digit. It is less than 5 so we round down to the nearest thousand.

Answer: 2000

Now let us do one with decimals.

Example 3: Round 4,25 off to the nearest unit or whole number.

4,25 lies on the number line between the units/whole numbers 4 and 5 . It is closer to 4 though. Also when rounding off the nearest whole number, we look at the tenths digit. It is less than 5 so we round down to the nearest whole number which is 4 .

Does everyone understand? Are there any questions?

Now let us use what we have learnt about rounding off to help us solve some problems:

Please solve the following:

1. $17 \div 4=$ ? Round your answer off to the nearest whole number.

2. Mr Farmer decides to share his 17 cows evenly between his 4 children. To avoid conflict, each child must receive the same number of cows. How many cows will each child get?

If you have the class work correct, please continue with the homework which is page 23 of your textbook, numbers $1-8$.

In the approach applied in the lesson vignette above, mathematics is viewed as a ready-made system with general applicability. Consequently, mathematics instruction is seen as a process of breaking up formal mathematical knowledge into learning procedures and then learning to use them accordingly.

Let us examine another similar problem to Example 3 above:

The problem: 17 people are trapped on a mountain and need to be rescued by helicopter. The helicopter can take a maximum of 4 passengers at a time, in addition to the pilot. How many trips will the helicopter need to make?
This example illustrates where conventional mathematics as we perform it outside of any prescribed context, can actually support or conflict with the answer depending on the context of the problem. In solving the problem above, it is the context that must take preference over the mathematical convention of rounding off "down" to the nearest whole number when our indicator is below 5. But when we teach mathematics predominantly formally and outside of context, do our students learn to know the difference between conventional mathematics and mathematics as a tool operating within a social context?

\section{Mathematics as a social construct}

Formerly (prior to the $20^{\text {th }}$ century) an absolutist view of mathematical knowledge dominated the philosophy of mathematics education. According to Ernest (1991), this view accepts that mathematics consists of absolute and unchallengeable truths that can be regarded as certain knowledge based on two types of assumptions in terms of the actual mathematics (axioms and definitions) and logic (axioms, rules of inference and the formal language and its syntax).

Early in the twentieth century a number of antinomies and contradictions, mainly in the theory of sets and functions, were derived in mathematics (Kline, 1980; Kneebone, 1963; Wilder, 1965 as cited in Ernest, 1991), which caused a crisis within this absolutist paradigm. The certainty of mathematics and its theorems was challenged by the appearance of these contradictions (i.e., falsehoods) resulting in the development of a number of schools in the philosophy of mathematics. These schools aimed to account for the nature of mathematical knowledge and to reestablish the certainty thereof. Ernest (1991) identifies the three major schools as being logicism, formalism and constructivism. Without elaborating on each school, it suffices to say that the former absolutist paradigm that dominated previously, undermined the social responsibility of mathematics in human affairs such as value, wealth and power (Ernest, 1991). The shift has challenged the infallibility of mathematics and acknowledged it as a product of human inventiveness (Davis \& Hersh, 1980) and a human activity (Freudenthal, 1973), thus making it a social construct. Ernest (1991, p. 42) specifies the grounds for describing mathematical knowledge as a social system: 
1. The basis of mathematical knowledge is linguistic knowledge, conventions and rules, and language is a social construction.

2. Interpersonal social processes are required to turn an individual's subjective mathematical knowledge, after publication, into accepted objective mathematical knowledge.

3. Objectivity itself will be understood to be social.

It therefore draws on conventionalism, in accepting that human language, rules and agreement play a central role, including the view that mathematical concepts develop and change. It also includes Lakatos' philosophical thesis that mathematical knowledge grows through conjectures and refutations. The above therefore constitutes the perspective from which the following questions are discussed in this paper:

- Why is teaching in context an important option to consider in the teaching of mathematics?

- What does it mean to teach mathematics from and in context?

- What are the possible challenges associated with this practice?

\section{The relevance of teaching in context}

Within the scope of this paper, two main answers to the first question are proposed. The first stems directly out of the shift in mathematics education already discussed from an absolutist paradigm to a more social constructivist view. This shift to emphasizing mathematics as a social construct is certainly supported by and demonstrated in the following definition of mathematics provided in the Revised National Curriculum Statement (RNCS) by the Department of Education (DoE, 2002, p. 4):

Mathematics is a human activity that involves observing, representing and investigating patterns and quantitative relationships in physical and social phenomena and between mathematical objects themselves. Through this process, new mathematical ideas and insights are developed. Mathematics uses its own specialised language that involves symbols and notations for describing numerical, geometric and graphical relationships. Mathematical ideas and concepts build on one another to create a coherent structure. Mathematics is a product of investigation by different cultures - a purposeful activity in the context of social, political and economic goals and constraints.
To fully embrace the extent of this definition and to realise the goals intended by the introduction of Mathematical Literacy as a compulsory subject, we need to consider teaching mathematics from and in context rather than in its absolute form for the purpose of later applying in contexts.

The second response to the first question lies within the results of both national as well as international studies carried out in mathematics education. In the systemic evaluation, South Africa's Grade 3 and Grade 6 learners performed poorly on the national average. In the 1999 and 2003 results of the Trends in International Mathematics and Science Study (TIMSS, 2003) South Africa once again was placed last out of the fifty countries that participated. Although a detailed discussion and analysis of factors causing such overall poor performance is beyond the scope of this paper (see Howie, 2001; 2002), it can be concluded that South African learners certainly struggle far more than the rest of the world when required to perform mathematics within a context.

Figures 1 shows examples of selected contextual items from TIMSS 2003. These items were identified (as examples not as conclusive proof) according to their applicability to contexts from everyday life that one might encounter. The performance of South African Grade 8 learners on the items in comparison to the international average and that of selected countries are also provided.

\section{Teaching in and from context - The theory of Realistic Mathematics Education}

In order to examine the second question, we draw on the work currently being done by the Freudenthal Institute in The Netherlands. They have been leaders in introducing and researching teaching mathematics in and from contexts in their theory known as Realistic Mathematics Education (RME). Realistic Mathematics Education has its roots in Freudenthal's interpretation of mathematics as a human activity (Freudenthal, 1973; Gravemeijer, 1994). To this end, Freudenthal accentuated that the actual activity of doing mathematics; an activity which he propagated, should predominantly consist of organising or mathematising subject matter taken from reality. Learners should therefore learn mathematics by mathematising subject matter from real contexts and their own mathematical activity rather than from the traditional view of presenting 
Item 1

A garden has 14 rows. Each row has 20 plants. The gardener then plants 6 more rows with 20 plants in each row.

How many plants are now there altogether?

Answer:

\section{Item 2}

A car has a fuel tank that holds $45 \ell$ of fuel. The car consumes $8,5 \ell$ of fuel for each $100 \mathrm{~km}$ driven. A trip of $350 \mathrm{~km}$ was started with a full tank of fuel. How much fuel remained in the tank at the end of the trip?
A. $15,25 \ell$
B. $16,25 \ell$
C. $24,75 \ell$
D. $29,75 \ell$

\section{Item 3}

The graph represents the distance and time of a hike taken by Joshua and Liam.

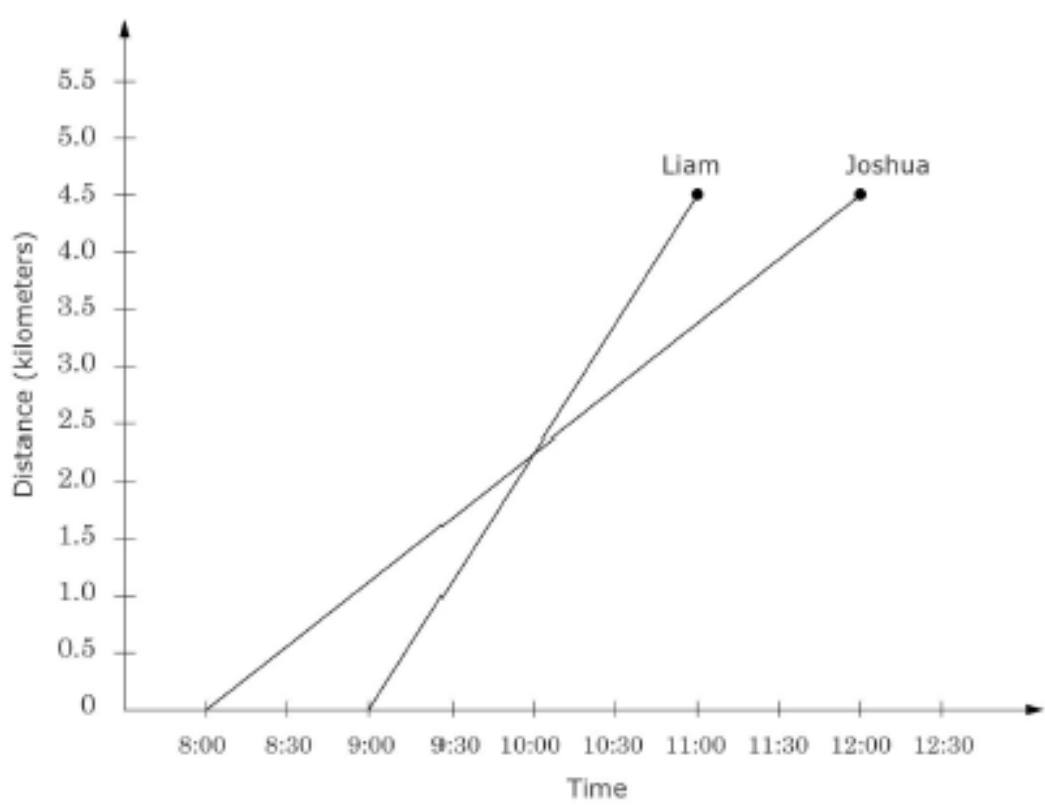

If they both started from the same place and walked in the same direction, at what time did they meet?
A. $\quad 8: 00$
B. $\quad 8: 30$
C. $\quad 9: 00$
D. $\quad 10: 00$
E. $11: 00$

Performance on the items

\begin{tabular}{|c|c|c|c|c|c|c|c|c|}
\hline & Int. Ave & RSA & Tunisia & Morocco & Egypt & Netherlands & NZ & USA \\
\hline Item 1 & 61,2 & $\mathbf{1 7 , 7}$ & 48,4 & 38,5 & 36,1 & 88,1 & 76,5 & 78,4 \\
\hline Item 2 & 26,0 & $\mathbf{1 8 , 0}$ & 18,7 & 18,9 & 20,6 & 37,9 & 23,6 & 24,8 \\
\hline Item 3 & 62,4 & $\mathbf{1 9 , 3}$ & 14,5 & - & 47,3 & 81,2 & 72,3 & 79,7 \\
\hline
\end{tabular}

Figure 1: Items from TIMSS (Source: TIMSS, 2003) 
mathematics to them as a ready-made system with general applicability (Gravemeijer, 1994). These real situations can include contextual problems or mathematically authentic contexts for learners where they experience the problem presented as relevant and real.

The verb mathematising or its noun mathematisation implies activities in which one engages for the purposes of generality, certainty, exactness and brevity (Gravemeijer, Cobb, Bowers \& Whiteneack, as cited in Rasmussen \& King, 2000). Through a process of progressive mathematisation, learners are given the opportunity to reinvent mathematical insights, knowledge and procedures. In doing so learners go through stages referred to in RME as horizontal and then vertical mathematisation (see Figure 2). Horizontal mathematisation is when learners use their informal strategies to describe and solve a contextual problem and vertical mathematisation occurs when the learners' informal strategies lead them to solve the problem using mathematical language or to find a suitable algorithm (Treffers, 1987). For example, in what we would typically refer to as a "word sum", the process of extracting the important information required and using an informal strategy such as trial and error to solve the problem, would be the horizontal mathematising. Translating the problem into mathematical language through using symbols and later progressing to selecting an algorithm such as an equation could be considered vertical mathematisation, as it involves working with the problem on different levels.

The traditional formal and authoritarian approach to teaching mathematics that has dominated in South African classrooms for a number of years has not afforded learners many opportunities to make use of horizontal mathematisation.
Mathematics lessons are often presented in such a way that the learners are introduced to the mathematical language relevant to a particular section of work and then shown a few examples of using the correct algorithms to solve problems pertaining to the topic before being given an exercise of worksheet to complete (Venter, Barnes, Howie, \& Janse van Vuuren, 2004). The exercises or worksheets are usually intended to allow learners to put the algorithms they have been taught into practice and may even contain some contextual problems that require the use of these algorithms. According to the RME model depicted in Figure 4, this type of approach places learners immediately in the more formal vertical mathematisation process. The danger in this is that when learners have entered that process without first having gone through a process of horizontal mathematisation, a strong possibility exists that if they forget the algorithms they were taught, they do not have a strategy in place to assist them in solving the problem. Low attainers often exhibit this lack of strategy. This experience can be equated to someone being shown and told what is on the other side of a river and being expected to use what is there for their own benefit. However, they are not given or shown the bridge that assists one in crossing to the other side in order to make proper use of what is there. The horizontal mathematisation process provides this bridge (Barnes, 2004).

When embarking on solving a contextual problem using formal mathematical knowledge, the following steps are usually followed. First the problem needs to be translated from its contextual state into mathematical terms. Available mathematical means are then drawn on in order to solve the problem, which then needs to be translated back into the original context. This process can be illustrated by the example we encountered earlier on:

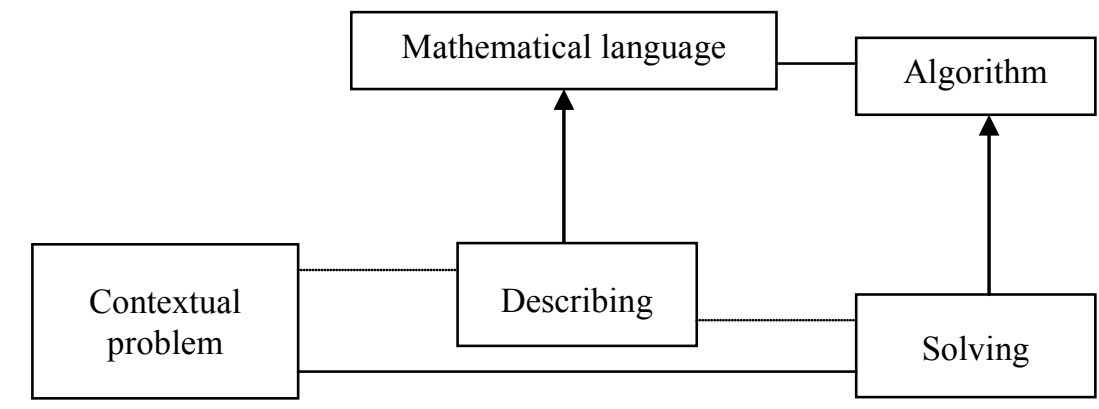

Horizontal mathematisation ( ); Vertical mathematisation (

Figure 2: Horizontal and vertical mathematisation Source: Adapted from Gravemeijer, 1994. 
The problem:

17 people are trapped on a mountain and need to be rescued by helicopter. The helicopter can take a maximum of four passengers at a time, in addition to the pilot. How many trips will the helicopter need to make?

Translation into mathematical terms: 17 people / 4 per trip

Mathematical means to solve problem:

$17 \div 4=4$ remainder 1 or $4 \frac{1}{4}$ or 4.25

Translation back into original context:

Helicopter will need to make 5 trips

On the other hand, in the RME problem-centred approach, the problem, rather than the use of a specific mathematical tool, is the actual aim. Instead of trying to formalise the problem into mathematical terms, the learners are encouraged to describe the problem in a way that makes sense to them. This can involve using their own selfinvented symbols or pictures and identifying the central relations in the problem situation. In this way the problem is also simplified for the learner. Because the symbols are meaningful for the problem-solver, further translation and interpretation of the problem is easier and using a standard procedure is not mandatory. In Boxes 1 and 2 below examples of contextual problems given to Grade 8 learners in a study using the theory of RME is presented (Barnes, 2004). Some responses from learners who took part in the study are then offered as a means to demonstrate the concept of mathematisation.

The above-mentioned study took the form of a case study of 12 participants in an urban school in South Africa. The learners were identified by their mathematics teachers as low attainers in mathematics. They were each part of a remediation programme in mathematics that these learners took part in while the rest of their class were enrolled for the subject of a third language. The participants were part of a mathematics intervention for two lessons per week for approximately three school terms. The intervention was designed and taught based on the principles of Realistic Mathematics Education. In summary the theory of RME proved to be viable tool in teaching mathematics to low attainers (Barnes, 2004).
Box 1

Lesson on the cat's pills

My cat's recent diagnosis of diabetes initiated this problem, which served as an introductory contextual problem in revisiting the concept of fractions. A discussion on what diabetes is and how it occurs in humans and cats was first embarked on with learners as an introduction (learners had little knowledge of diabetes and were not easy to convince that cats also get diabetes). Learners were then presented with and asked to solve the following problem (either in groups or individually; they were given the choice):

Problem:

My cat needs to take two types of pills and an insulin injection twice a day to control its diabetes. The cat takes half a big pill in the morning and again in the evening and a quarter of a small pill also in the morning and again in the evening. Firstly, the vet has given me 17 big pills and 27 small pills to start off with, how many days will these pills last me for before I have to go back to get more? Secondly, how many of each pill should I buy each month so that they last me for a whole month?

About ten minutes before the end of the lesson, some learners were asked to demonstrate and explain their solutions to the class and a short whole class discussion on these explanations was held before the class was dismissed.

The solutions offered by Liya to the contextual problem provided in Box 1 are shown in Figures 3 and 4 to exemplify this (RME) process of problem solving. There are two parts to the solution as Liya first tried Part A (Figure 3) and then realised from her answers that something was not right and then proceeded to do the solution in Figure 4. It is also interesting to note how her Part A solution more closely resembles the steps usually followed when using formal mathematical knowledge in an information processing approach.

As these learners were probably more accustomed to using the more formal approach, and obviously had some formal knowledge in place regarding fractions, they initially often tried to go through the steps of translation into mathematical terms, searching for an adequate mathematical procedure to solve the problem and then translating it back to the context. In doing so though, it was noticed that some learners did not really have a grip on which mathematical procedure to use and even when they chose the correct one (sometimes by chance as they could not justify their decisions), they made mistakes in executing them (as can be seen in Part A of Liya's solution). 


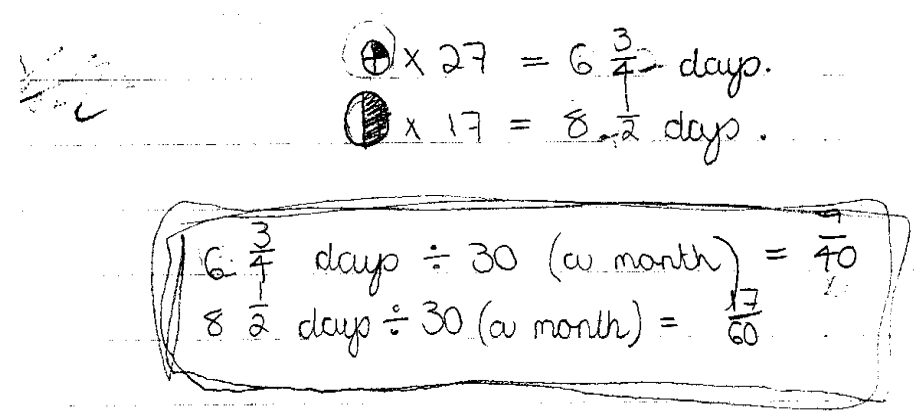

Figure 3: Part A of Liya's solution to the cat pills problem

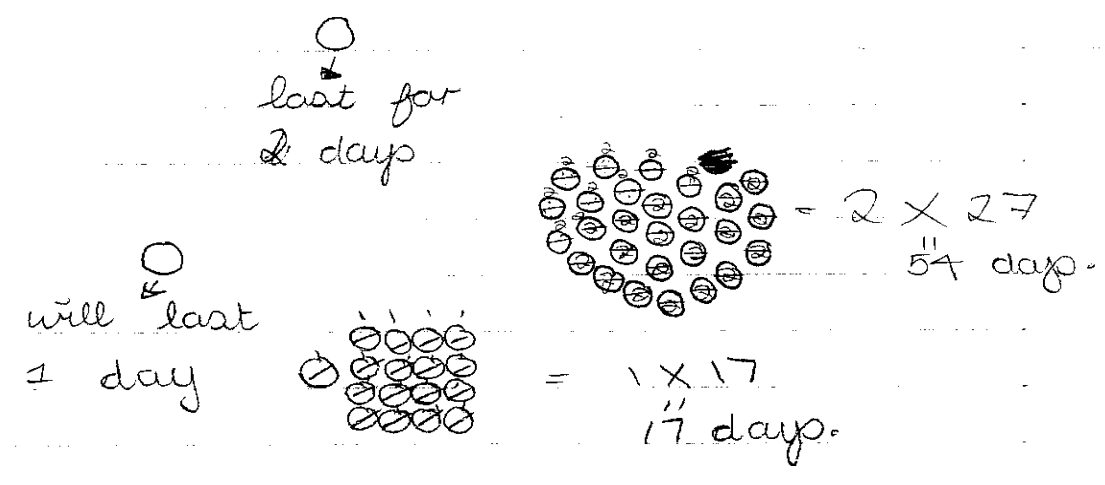

Figure 4: Part B - Liya's second attempt at solving the cat pills problem

During the course of the study (Barnes, 2004) an effort was continually made to encourage learners to go through the RME approach of simplifying the contextual problem by first representing it in their own symbols and/or words and then further solving and interpreting it from there. When some of them started to do this, they found that they could more often solve the problem, using their informal strategies rather than formal procedures they were unsure of. This does not mean that they never used formal procedures or any mathematical means but that they were expected to only use them at a point in the problem-solving process when they could justify the use thereof and demonstrate an understanding of the application in that regard.

\section{Box 2}

You decide to start making banana bread to sell in order to earn some extra money. To start off with, you decide to make 5 loaves of banana bread. According to the recipe, each loaf requires $4 \frac{1}{2}$ bananas. How many bananas will you need to make the 5 loaves of banana bread? Show your working out in the space provided below.
As can be seen in Zwanela's solution (Figure 5), she correctly selected multiplication as her strategy. However, when she executed the actual multiplication, she tried to change the mixed number into an improper fraction and in doing so "lost" the denominator and got 9 instead of $\frac{9}{2}$, rendering her final answer incorrect. Zwanela often resorted immediately to vertical mathematisation in that she searched for the "correct" formal procedure to apply. In contrast to Zwanela's more formal solution, the use of horizontal mathematisation is more evident in the solution from Violet (Figure 6).

Gravemeijer (1994) explains that by getting learners to solve a sequence of similar problems, another process is induced. The problem descriptions develop into an informal language, which is further simplified and formalised into a more formal mathematical language eventually. A similar process could be experienced in terms of the solving procedure, where solving similar kinds of problems becomes routine and actual algorithms take shape. Through this learning process, formal mathematical knowledge itself can be constructed. 


\section{Arm to make fire loaves of banana bread.}

$$
\begin{aligned}
& 4 \frac{1}{2} \times 5 \text { lcaves. } \\
& 4 \frac{1}{2} \times 5 \\
& 9 \times 5=45 .
\end{aligned}
$$

Figure 5: Zwanela's solution to the banana bread problem

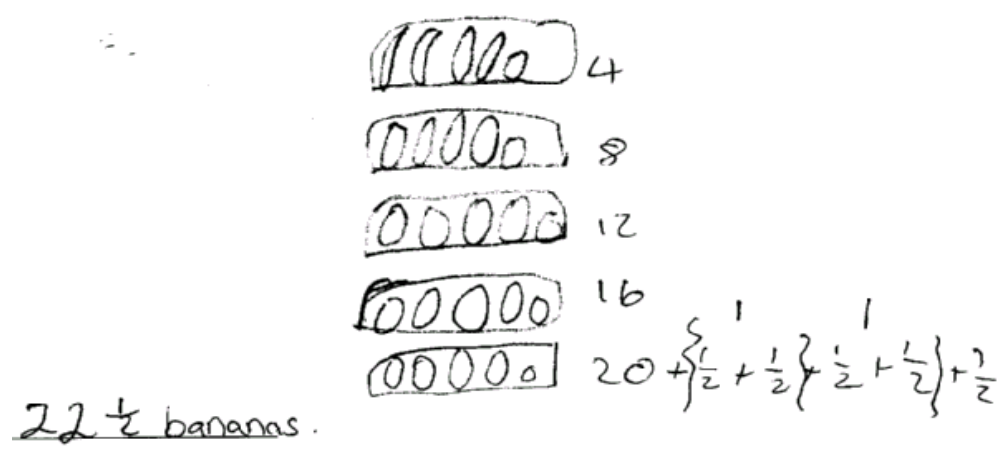

Figure 6: Violet's solution to the banana bread problem

\section{RME at tertiary level}

International studies (Doorman, 2001; Streefland, 1991; Treffers, 1987; Vos, 2002), including studies from developing countries such as Indonesia (Armanto, 2002; Fauzan, 2002) have shown that the RME theory is a promising direction to improve and enhance learners' understanding in mathematics in primary and secondary schools. So how can the theory of RME be employed in tertiary education?

Kwon (2002) provides one example of how an RME design could be used for teaching an introductory course in differential equations at first year university level. The teaching experiment was conducted with a group of 43 students and data consisted of videotapes, field notes, copies of students' work and records of instructional activities and decisions. Materials implemented during the course were informed by RME instructional heuristic and designed to assist students to complete reinvention activities through devising their own ways of working through mathematical concepts (also known as the inquiry-oriented approach). An explicit intention of Kwon's project was to create a learning environment where students routinely offered explanations of and justifications for their explanations. A typical class period entailed students working in groups of two to four on a task presented by the instructor. Cycles of whole class discussions and further group work then followed. A continuous emphasis on reasoning and whole class discussions resulted in key concepts emerging.

In a later evaluation study (Rasmussen, Kwon, Allen, Marrongelle \& Burtch, 2004 as cited in Kwon, 2005) two groups of students from four undergraduate institutions in Korea and the USA were compared in terms of their understanding of central ideas and analytical methods relating to differential equations. One group was exposed to an inquiry-orientated approach based on the theory of RME. The other group, however, was taught in the traditional lecture-based manner, where a typical class consists of a review of previous work, presentation of new work and some time for students to work on their own or ask for assistance (Romberg, 2001). There was no significant difference between the two groups on routine problems. However, the inquiry-orientated group did score significantly higher than the comparison (traditional lecture-based) group on the conceptual problems. 
Even after a delayed post-test a year later, Kwon (2005) inferred that retention rates on procedural tasks showed no significant difference, but that retention on conceptual tasks were significantly different between the groups. Once again the inquiry-orientated group scored significantly higher than the traditional group on the conceptually oriented items. In addition, Kwon found that all the inquiry-oriented students out-performed the traditional group regardless of academic background or gender. This finding has important implications for the South African context when transition from school level practices to that of tertiary levels is made, especially when the quality of diverse school experiences are considered.

As also demonstrated by Skemp's (1971) distinguished between relational and instructional understanding, a chasm may exist between what students are able to do and what they in fact understand. Knowing what to do in a specific situation, but not necessarily understanding why it works, may limit the transfer of that procedure or skill. The increasing number of procedures that students need to commit to memory in mathematics often results in learners in secondary school and students at tertiary level becoming confused or partly remembering and trying to apply procedures they have never fully understood (Daniels \& Anghileri, 1995). Understanding on the other hand promotes remembering and enhances transfer owing to the reduced number of bits of knowledge that need to be simultaneously held in the short-term memory (Hiebert \& Carpenter, 1992). The understanding that comes from making connections, seeing how things fit together, relating mathematics to real situations and articulating patterns and relationships also carries with it a satisfaction which can further motivate students (Haylock, 1991). Exposure to constructing mathematics at an early level could promote the construction of mathematics at higher levels and generating of new knowledge to the domain. Compared to the more formal approach of teaching mathematics we have become accustomed to, teaching in context appears to be a vehicle through which our would-be mathematicians can express and develop themselves mathematically and thus enrich the South African community in terms of financial, economical and scientific models for living.

\section{Some challenges}

Although a necessary and positive shift, teaching in context does not come without its challenges. In a heterogeneous society such as in South Africa where we have eleven official languages, the issue of language comes to the fore as a potential hurdle. Research pertaining to proficiency in language as a factor in the learning of mathematics is certainly available and still currently being conducted (Howie, 2002; Setati, 2002). Conclusive evidence of the impact of the Language of Learning and Teaching not being in the mother-tongue is not yet available though and remains a controversial issue. When teaching in context, it is obviously important that the language of the problem be accessible to the students. In our situation visual aids, such as graphs, tables and diagrams can assist students in this regard. Employing simple language that is not ambiguous is also necessary.

Also relating to language is the actual selection of the context from which the development of certain mathematics is to evolve. The context of the problem needs to be accessible within the framework of the student so that they are able to set about solving the problem, rather than getting lost or caught up in the context. Kwon (2005) also makes the point that the tasks need to be carefully selected or designed as learning is not necessarily implied through solving a sequence of problems. This in turn calls for a high level of subject matter knowledge and understanding of the substantive and syntactic structures of the discipline of mathematics (Grossman, Wilson \& Shulman, 1990) for both designers and teachers.

Linking to this is the issue of material development. As Bowie and Frith (2006) discovered in their process of developing mathematical literacy materials, when one attempts to mathematise a context, it is necessary to have a good understanding, not only of mathematics, but also of the context. Mathematical literacy teachers in South Africa already therefore need to familiarise themselves with contexts such as "voting systems, mortgages, retirement funding, HIV/AIDS, global positioning systems and socially responsible trade (to name but a few of the contexts suggested in the current curriculum)" (Bowie \& Frith, 2006, p.33). The learners and students themselves also need to be able to understand the context and in our diverse country we cannot, for example, assume that all learners are familiar with the notion of a formal banking system or the concept of risk and return on investments. In order to successfully implement $\mathrm{RME}$, this issue of appropriate contexts will also need to be resolved. Bowie and Frith (2006) suggest integration of knowledge and skills across 
subjects and terrains of practice as a possible solution in addressing this issue. They stress that this integration needs to be worked in at a curriculum level in order for it to be taken seriously. But our teachers are under enough pressure in coping with the constant curriculum changes. It is our opinion that we need to start supplying teachers with materials that enable them to teach using an RME approach.

At school level a number of learning materials based on the theory of RME are already available in The Netherlands, the United States and the United Kingdom. We could consider recontextualising these for a South African context. At tertiary level, not many such materials have been developed. However, a strong developmental research partnership between mathematicians and mathematics educators could facilitate such a process. Wittmann (1998 as cited in Julie, 2006) identifies the central task of Mathematics Education, as a field of study, as developing learning resources for productive and meaningful learning. He argues that teachers do not have the time to do this and that one of the main roles of mathematics educators is to therefore carry out the didactical analysis of subject matter in designing the resources. This is done through "theorisation and thought-experimentation which leads to hypothetical learning trajectories" (Julie, 2006: 64). These hypothesised trajectories then need to be trialled, researched and further developed within real classroom situations in order to decrease the distance between the intended and implemented curriculum (Julie, 2006). The RME materials mentioned above have been developed in such a manner within their respective countries (see Gravemeijer, 1998; Gravemeijer \& Cobb, 2002; Treffers \& Goffree, 1985). A replication of a similar process in South Africa would help us to re-contextualise the materials for a South African context as well as assist in capacity building where classrooms become research domains and sites of experimental implementation (Julie, 2006).

Finally, having discussed language, contexts and material development, we cannot omit our main challenge (and source of success) in implementing a theory such as Realistic Mathematics Education, namely teachers. Curriculum developers can produce material in context to be used in mathematics classrooms, but this does not necessarily mean that teachers will implement these as intended. For teaching mathematics in context, a methodology change is required that challenges the learners to become more independent thinkers in order to become better problem-solvers as well as mathematicians. The theory of RME encourages an approach that treats each individual student of mathematics as a mathematician with the capacity to mathematise contexts into mathematical problems that can be solved (Freudenthal, 1983). Teachers who attempt to teach mathematics in context through a more traditional approach of giving an example and then expecting learners to practise applying the tools to a range of contextual problems have missed the point. It is therefore necessary in training mathematics teachers to teach in context, to develop the skills needed to be able to relate mathematics and context (Brown \& Schafer, 2006) in a more problem-solving or inquiry oriented approach. An important skill that needs to be foregrounded in this regard is that of interpreting mathematical concepts and skills in relation to a context (Brown \& Schafer, 2006). Having not learnt mathematics at school or university through such an approach, we cannot assume that our mathematics teachers, even those proficient in mathematics, have mastered this skill. Equipping teachers to teach in context will therefore require extensive and continued training. Academic institutions willing to form partnerships with schools where mathematics educators, mathematicians and mathematics teachers could work together in developing, implementing and researching an approach of teaching in context, would go a long way to making such a venture successful.

\section{Conclusion}

This paper has sought to examine the issue of teaching mathematics in context as a social construct, using the theory of Realistic Mathematics Education. We are of the opinion that our current mathematical practises are still not foregrounding the shift from the absolutist paradigm to social constructivism and adequately empowering our learners. This has further implications for them as students at tertiary institutions as well as effective citizens within our democracy. While teaching in and from context is not without its challenges, especially within our diverse society, it appears to hold potential as a vehicle with which to address this problem, both at school and tertiary level. Mathematics lecturers are encouraged to reflect on their own practices in the teaching of mathematics and to consider partnering with mathematics educators (from schools and tertiary institutions) to work on designing classroom experiments that engender a culture of mathematising amongst our students. 


\section{References}

Armanto, D. (2002). Teaching multiplication and division realistically in Indonesian primary schools: A prototype of local instruction theory. Unpublished doctoral dissertation. University of Twente, The Netherlands.

Barnes, H. E. (2004). A developmental case study: Implementing the theory of Realistic Mathematics Education with low attaining learners. Unpublished Masters dissertation. University of Pretoria, South Africa.

Bowie, L. \& Frith, V. (2006). Concerns about the South African Mathematical Literacy curriculum arising from experience of materials development. Pythagoras, 64, 29-36.

Brown, B. \& Schäfer, M. (2006). Teacher education for Mathematical Literacy: A modelling approach. Pythagoras, 64, 45-51.

Daniels, H. \& Anghileri, J. (1995). Secondary mathematics and special educational needs. London: Cassell.

Davis, P.J. and Hersh, R. (1980). The mathematical experience. Harmondsworth: Penguin.

Department of Education (2002). Annual Report. Retrieved 21 March 2003 from http://education.pwv.gov.za/Policies\%20and $\% 20$ Reports/2002_Reports

Doorman, M. (2001). How to guide students? A reinvention course on modeling movement. Paper presented at The Netherlands and Taiwan conference on common sense in mathematics education, Taipei, Taiwan. Retrieved 22 April 2003 from www.fi.ruu.nl/en/publications.shtml

Ernest, P. (1991). The philosophy of mathematics education. Hampshire: Falmer Press.

Fauzan, A. (2002). Applying Realistic Mathematics Education (RME) in teaching geometry in Indonesian primary schools. Unpublished doctoral dissertation. The Netherlands, Enschede: University of Twente.

Freudenthal, H. (1973). Mathematics as an educational task. Dordrecht: Reidel.

Freudenthal, H. (1983). Didactical phenomenology of mathematical structures. Dordrecht: Reidel.

Gravemeijer, K., \& Cobb, P. (2002). Designing classroom-learning environments that support mathematical learning. Paper presented at the American Educational Research Association conference in April 2001.

Gravemeijer, K.P.E. (1994). Developing Realistic Mathematics Education. Utrecht: Freudenthal Institute.

Gravemeijer, K.P.E. (1998). Developmental research as a research method. In A. Sierpinska \& J. Kilpatrick (Eds.), Mathematics education as a research domain: A search for identity (Book 2, pp. 277-295). Dordrecht: Kluwer.
Grossman, P.L., Wilson, S.M., \& Shulman, L.S. (1990). Teachers of substance: Subject matter knowledge for teaching. In M. Reynolds (Ed.), Knowledge base for the beginning teacher. New York: Pergamon.

Haylock, D. (1991). Teaching mathematics to low attainers, 8-12. London: Paul Chapman.

Hiebert, J., \& Carpenter, T.P. (1992). Learning and teaching with understanding. In D. Gouws (Ed.), Handbook for research on mathematics teaching and learning (pp. 65-97). New York: MacMillan.

Howie, S.J. (2001). Mathematics and science performance in Grade 8 in South Africa 1998/1999: TIMSS-R 1999 South Africa. Pretoria: Human Sciences Research Council.

Howie, S.J. (2002). English language proficiency and contextual factors influencing mathematics achievement of secondary school pupils in South Africa. Unpublished doctoral dissertation. University of Twente, The Netherlands.

Julie, C. (2006). Mathematical Literacy: Myths, further inclusions and exclusions. Pythagoras, 64, 62-69.

Kwon, O. (2002). Conceptualizing the Realistic Mathematics Education approach in the teaching and learning of ordinary differential equations. Paper presented at the 2nd International Conference on the Teaching of Mathematics, Greece. Retrieved 8 December 2009 from www.eric.ed.gov/ERICDocs/data/ericdocs2sql/co ntent_storage_01/0000019b/80/1a/ad/9d.pdf

Kwon, O. (2005). Towards inquiry-oriented mathematics instruction in the university. Proceedings of KAIST International Symposium on enhancing university mathematics teaching, May 2005, Daejeon, Korea. Retrieved 8 December 2009 from http://mathnet.kaist.ac.kr/real/2005/8/OhNamKwo n.pdf

Rasmussen, C.L., \& King, K.D. (2000). Locating starting points in differential equations: A realistic mathematics education approach. International Journal of Mathematical Education in Science and Technology, 31, 161-173.

Romberg, T. A. (2001). Mathematical Literacy: What does it mean for school mathematics. Wisconsin School News, October 2001.

Setati, M. (2002). Language practices in multilingual classrooms in South Africa. Unpublished doctoral dissertation. University of the Witwatersrand, South Africa.

Skemp, R. (1971). The psychology of learning mathematics. Harmondsworth, UK: Penguin.

Skemp, R. (1989). Mathematics in the primary school. London: Routledge.

Streefland, L. (1991). A paradigm of developmental research. Dordrecht: Kluwer Academic. 
TIMSS (2003). Released Items: Eighth Grade Mathematics. Retrieved 2 November 2006, from http://timss.bc.edu/PDF/T03_released_M8.pdf

Treffers, A. (1987). Three Dimensions - A model of goal and theory description in mathematics instruction. Dordrecht: Kluwer Academic.

Treffers, A., \& Goffree, F. (1985). Rational analysis of Realistic Mathematics Education - the Wiskobas program. In L. Streefland (Ed.), Proceedings of the Ninth International Conference for the Psychology of Mathematics Education, 2, 97-121.
Venter, E., Barnes, H., Howie, S.J, \& Jansen van Vuuren, S. (2004). Mpumalanga Secondary Science Initiative - Learner Progress Research Project. Pretoria: Centre for Evaluation and Assessment.

Vos, P. Like an ocean liner changing course: The grade 8 mathematics curriculum in the Netherlands, 1995-2000. Unpublished doctoral dissertation. University of Twente, The Netherlands. 